\title{
Sport for the Spinal Paralysed Person
}

R. W. Jackson, M.D., M.S., F.R.C.S.(C)

Chief of Surgery, Orthopaedic and Arthritic Hospital, 43, Wellesley Street East, Toronto, Ontario M4 Y 1HI, Canada

\section{Brief historical note}

Sir Ludwig Guttmann was knighted in 1966 for his many contributions to the treatment of paraplegia, including the use of sport as a therapeutic measure. The history of the Spinal Injuries Unit at Stoke Mandeville, and the development of the International Stoke Mandeville Games has been documented on several occasions (Jackson and Davis, 1983). However, it is worth noting that from this humble therapeutic beginning in 1948, sport for the disabled has, in a mere 39 years, grown into a major worldwide entity. Some of the key points in this growth were:

1960 - the first wheelchair olympics were held immediately after the regular Olympics in Rome.

1976-the Olympiad for the Physically Disabled, in Toronto, was the first major sporting event in which blind and amputee athletes, joined with paralysed athletes in competition.

1980-formation of the International Coordinating Council-the governing body for sport for disabled athletes due to any cause.

1984-inclusion of demonstration events by disabled athletes in both the winter (Sarajevo) and summer (Los Angeles) Olympic games.

\section{Organisational structures}

The International Stoke Mandeville Games Federation (I.S.M.G.F.) is the governing body for wheelchair sport. Most of the competitors are disabled because of spinal paralysis or polio, but some competitive athletes are amputees who normally use a wheelchair instead of a prosthesis. Each member country, (approximately 50), is represented on the Sports Council, and the Executive Committee and Officers are democratically elected from this Council. A permanent office is based at the Ludwig Guttmann Sports Center under the direction of Miss Joan Scruton, the Secretary General. The Executive Committee of I.S.M.G.F. liaises with representatives of blind sports, amputee sports and cerebral palsy sports, through the International Coordinating Committee (I.C.C.).

At the member country level, there is a great variety of organisational structures. In some of the smaller countries, sports programmes are organised by 
rehabilitation centres and involve only a few individuals. In some of the larger countries, such as Canada, there are both local (provincial) and national organisations which co-ordinate activities at their respective levels. The athletes who are chosen to represent Canada at any international event (such as the Annual Stoke Mandeville Games) have been winners in local, regional and national games, before being selected for the international team.

In most countries, the activities of disabled athletes are recognised by their governments and supported to a significant degree through funds allocated for sports purposes. In this respect, wheelchair athletes have generally gained the respect and status of able-bodied athletes, and have shown that first, they are athletes, and second, athletes that require a wheelchair to compete.

\section{Sporting activities}

A wide range of sporting activities at different levels of participation, are currently available for the disabled individual (Guttmann, 1976). During the rehabilitation process, sport is usually offered as a means of improving stamina, strength and skill in the use of a wheelchair. Basketball is a commonly used therapeutic tool, as are archery, table-tennis and wheelchair racing. Swimming, is also an excellent way to regain upper body strength and physical fitness. Skill sports such as snooker, bowling, rifle and pistol shooting, are also available for those with competitive desires, but who can no longer participate in the strength sports. This diversity of sporting activities provides an outlet for every individual's personal taste.

Increasing attention is now being directed towards the next phase, which involves recreational activities. Many of the sports that are introduced during rehabilitation, can be continued for pleasure, throughout the individual's life time. Other recreational activities include wheelchair tennis, sled skiing, sailing, fencing and many other diverse sports.

Should the individual wish to enter into competitive athletics, he or she must be dedicated, committed to training, and possess a strong desire to win. Specialisation has become necessary in order to even qualify for an event, as minimum standards for eligibility to compete are now commonplace.

\section{Benefits of sport to individuals}

\section{Physical}

The benefits of sport to the individual include increased strength, increased stamina, increased fitness and increased mobility. Numerous studies of wheelchair athletes at international games have shown the athletes to be more physically adapted to a life in a wheelchair than their less active and non-athletic counterparts. The question always arises as to whether or not these active individuals achieved an increased level of self-sufficiency through participation in sport, or whether they already possessed the appropriate attitudes and abilities, and therefore, became achievers in sport. The evidence tends to support the first hypothesis, which implies that participation in athletics tends to improve the individual's ability to 'wheel' and therefore, makes the problems 
encountered in daily life much easier to surmount. In this day and age where fitness can be physiologically monitored and quantified, studies have shown that paraplegics who were physically active at least two times a week are in better physical condition than similar individuals who live a sedentary life in a wheelchair. (Jackson and Davis, 1983; Kofsk et al. 1983; Nakamura, 1973).

\section{Psychological}

There is increasing evidence to support the hypothesis that those who pursue a physical lifestyle, have a better mental outlook and a better acceptance of their disability, than those who are relatively inactive. Psychological testing has shown a higher level of self-satisfaction, a greater self image, fewer suicidal tendencies and a more independent attitude in the athletes tested, than in those who are completely dependent on others and relatively inactive (Jackson and Davis, 1983; Nakamura, 1973). It is also quite obvious (although without scientific corroboration) that an individual who is chosen to represent his country in an international event, has a tremendous psychological uplifting, due to the pride induced by such success. Moreover, should the individual win for his country, there is an even greater boost to personal morale. Also, to be able to travel, to visit other countries, and to meet other people with similar problems, and different ways of handling those problems, is an opportunity which is extremely rewarding. Granted, such opportunities could come about through cultural exchanges such as music, science and literature but at the present time, such exchanges, outside of sport, are not common.

\section{Attitudinal adjustment}

Through sports, the attitudes of both the public and the handicapped individual are more easily adjusted. The public is interested when a wheelchair athlete does something extraordinary, such as the wheelchair odessey, (25000 miles around the world) conducted by the Canadian athlete, Rick Hansen. It is possible that a prospective employer will think more kindly of a job applicant in a wheelchair, if he is aware that at least one such handicapped individual was able to wheel around the world. Such publicity, therefore, tends to benefit all disabled. Some handicapped people are critical of such physical efforts, saying that it makes the rest of the disabled community look inadequate if they cannot achieve the same feats. However, the positive side of such endeavours is more important, and I believe that all of the disabled benefit in some way, from the achievements of the elite athletes.

Also, through athletics, not only are mental barriers diminished, but physical barriers are eliminated. Accessibility to buildings, wider elevator and bathroom doors in hotels, and wider supermarket check-out counters to allow a wheelchair to pass through, are all tangible examples of increased public awareness and appropriate legislation, designed to solve the problems of the wheelchair user. At the 'man in the street' level, the individual in a wheelchair is no longer regarded as a freak who might become sick, babble incoherently or fall out of his chair. These attitudinal adjustments are extremely important and have been promoted to a significant degree through sport. 


\section{Technological advances}

Through sport and the technology that has been pioneered on the race track, better wheelchairs are now available for the average wheelchair user. Rick Hansen, in crossing vast areas of snow-covered ground on his round the world odyssey, has been evaluating a four-wheel drive wheelchair. The technology that evolves from this experimental wheelchair, will eventually be refined, and made available for the average wheelchair user. Hansen has also been evaluating clothing for use in extreme cold temperatures. Electronic sensors monitor his skin temperature in the insensitive areas and regulate electrical heating controls, that prevent frostbite from occurring. Such technological advancements are only part of the legacy that sport endows on the average disabled individual.

\section{The future}

Sport for the disabled is moving steadily towards a normalisation of competition in each type of sport. Rules and regulations are only minimally altered to enable a wheelchair athlete to participate in a sport, whether it be archery, basketball, weight-lifting or track and field. Ideally, the organisations that govern each ablebodied sport, will eventually have a section on wheelchair sport in their rule book. This integration into normal sport is the goal of most of the competitive wheelchair athletes. The next major step will be the inclusion of one or more wheelchair events in the regular Olympics, not as demonstrations, but as actual competition, with the presentation of medals.

\section{Conclusion}

While still a valuable rehabilitation tool in the treatment of paraplegia, sport has broadened its scope to become both recreational and competitive. Large numbers of individuals recognise the physical benefits of sport in terms of increased fitness, strength, stamina and endurance resulting in better wheelchair mobility. On the psychological side, those involved in sport have more fun, more self assurance, and gain self satisfaction through competition and possibly winning. The elite wheelchair athelete has also opened the eyes of the public to the potentials of the disabled and has pioneered many changes in technology and in attitudes that will benefit the average wheelchair user in the future.

\section{References}

Guttmann L 1976 Textbook of Sport for the Disabled. Aylesbury, England. H.M. and M. Publishers

JACKSON RW, DAvis GM 1983 The value of sport and recreation for the physically disabled. Ortho. Clinics of N.A. Vol. 14, No. 2, pp 301-315

Kofsky PR, DAvis GM et al. 1983 Field Testing: Assessment of Physical Fitness of Disabled Adults. European Journal of Applied Physiology No. 51, pp 109-120

KOFSKY PR, SHEPHARD R, JACKSON RW 1985 Psycho-Social Factors \& Lifestyle Habits of Lower Limb Disabled Adults. Presented at the V International Symposium on Adapted Physical Activity, Toronto

NaKamura Y 1973 Working ability of the paraplegics. Paraplegia 11: 182-193

Zwiren L, BAR-Or O Responses to Exercise of Paraplegics Who Differ in Conditioning Level 